\title{
Systematic Review \\ Not Only Mania or Depression: Mixed States/Mixed Features in Paediatric Bipolar Disorders
}

\author{
Delfina Janiri ${ }^{1,2,+}$, Eliana Conte ${ }^{1,3,+}$, Ilaria De Luca ${ }^{1}$, Maria Velia Simone ${ }^{1}$, Lorenzo Moccia ${ }^{1}$, \\ Alessio Simonetti ${ }^{1,4}$, Marianna Mazza ${ }^{1}{ }^{1}$, Elisa Marconi ${ }^{1,5}{ }^{1}$, Laura Monti $^{1}$, Daniela Pia Rosaria Chieffo ${ }^{6}$, \\ Georgios Kotzalidis ${ }^{7}$, Luigi Janiri ${ }^{1,5}$ and Gabriele Sani ${ }^{1,5, *(\mathbb{D}}$
}

1 Department of Neuroscience, Section of Psychiatry, Università Cattolica del Sacro Cuore, 00100 Rome, Italy; delfina.janiri@uniroma1.it (D.J.); eliana.conte01@icatt.it (E.C.); ilaria.deluca02@icatt.it (I.D.L.); mariavelia.simone01@icatt.it (M.V.S.); lorenzo.moccia@policlinicogemelli.it (L.M.); Alessio.Simonetti@bcm.edu (A.S.); marianna.mazza@policlinicogemelli.it (M.M.); elisa.marconi@guest.policlinicogemelli.it (E.M.); laura.monti@policlinicogemelli.it (L.M.); luigi.janiri@unicatt.it (L.J.)

2 Department of Psychiatry and Neurology, Sapienza University of Rome, 00168 Rome, Italy

3 Eating Disorders Treatment Unit, Casa di Cura Villa Armonia Nuova, 00100 Rome, Italy

4 Menninger Department of Psychiatry and Behavioral Sciences, Baylor College of Medicine, Houston, TX 77030, USA

5 Department of Psychiatry, Fondazione Policlinico Universitario Agostino Gemelli IRCCS, 00100 Rome, Italy

6 Clinical Psychology Unit, Fondazione Policlinico Gemelli IRCCS, 00168 Rome, Italy; danielapiarosaria.chieffo@policlinicogemelli.it

7 NESMOS Department, Faculty of Medicine and Psychology, Sapienza University of Rome, Rome, Italy; giorgio.kotzaidis@uniroma1.it

check for updates

Citation: Janiri, D.; Conte, E.; De Luca, I.; Simone, M.V.; Moccia, L.; Simonetti, A.; Mazza, M.; Marconi, E.; Monti, L.; Chieffo, D.P.R.; et al. Not Only Mania or Depression: Mixed States/Mixed Features in Paediatric Bipolar Disorders. Brain Sci. 2021, 11, 434. https://doi.org/10.3390/ brainsci11040434

Academic Editor: Kymberly Young

Received: 26 February 2021

Accepted: 25 March 2021

Published: 29 March 2021

Publisher's Note: MDPI stays neutral with regard to jurisdictional claims in published maps and institutional affiliations.

Copyright: (c) 2021 by the authors. Licensee MDPI, Basel, Switzerland. This article is an open access article distributed under the terms and conditions of the Creative Commons Attribution (CC BY) license (https:// creativecommons.org/licenses/by/ $4.0 /)$.
* Correspondence: gabriele.sani@unicatt.it; Tel.: +39-063355896764; Fax: +39-063051343

+ Both authors contributed equally to this work.

\begin{abstract}
Background: early onset is frequent in Bipolar Disorders (BDs), and it is characterised by the occurrence of mixed states (or mixed features). In this systematic review, we aimed to confirm and extend these observations by providing the prevalence rates of mixed states/features and data on associated clinical, pharmacological and psychopathological features. Methods: following the Preferred Reporting Items for Systematic Reviews and Meta-Analyses (PRISMA) guidelines, we searched from inception to 9 February 2021 for all studies investigating mixed states/mixed features in paediatric BD. Data were independently extracted by multiple observers. The prevalence rates of mixed states/features for each study were calculated. Results: eleven studies were included in our review, involving a total patient population of 1365 individuals. Overall, of the patients with paediatric age BD, 55.2\% had mixed states/features (95\% CI 40.1-70.3). Children with mixed states/features presented with high rates of comorbidities, in particular, with Attention Deficit Hyperactivity Disorder (ADHD). Evidences regarding the psychopathology and treatment response of mixed states/features are currently insufficient. Conclusions: our findings suggested that mixed states/features are extremely frequent in children and adolescents with BD and are characterised by high levels of comorbidity. Future investigations should focus on the relationship between mixed states/features and psychopathological dimensions as well as on the response to pharmacological treatment.
\end{abstract}

Keywords: mixed state; mixed features specifier; bipolar disorder; childhood; adolescence; prevalence

\section{Introduction}

Bipolar disorders (BDs) consist of manic, depressive, and mixed episodes, which may be separated by periods of euthymia. Mixed episodes were considered those episodes meeting criteria for both mania and depression in the DSM-III to DSM-IV-TR editions, while the DSM-5 introduced the "with mixed features" specifier, which could apply to 
any type of episode of BD and major depressive disorder (MDD). Currently, in the DSM5, for manic/hypomanic episodes to meet criteria for mixed-features specifier, at least three depressive symptoms should be present nearly every day whereas, for a depressive episode to meet the same specifier, three manic/hypomanic symptoms should be present during the majority of days. Mixed states were described for the first time in ancient Greece and the Roman Empire (Aretæus of Cappadocia, 2nd Century (A $\rho \varepsilon \tau \alpha \tilde{\text { Io }} \zeta$ )), but not related to BD until 1899, when Emil Kraepelin (1856-1926) and his disciple Wilhelm Christian Jakob Karl Weygandt [1,2] described with extreme clarity the disease entity of manic-depressive illness. Thereafter, the first edition of the DSM classified cases with marked mixtures of the cardinal manifestations of mania and depression (mixed type). The subsequent editions applied the term "mixed" to similar concepts. However, a specific interest for mixed states appeared in the medical literature in the 1990s, and this was by Italian investigators [3-5] and one Armenian-American author [6]. Koukopoulos and his group, in particular, further pushed the mixed state to include agitated depression, at odds with the DSM-IV [7] distancing themselves from the DSM-5 [8], and contributed to finetuning the current concept [9]. Subsequently, other studies demonstrated that the clinical picture of mixed states is associated with a more severe form of $\mathrm{BD}$. According to a recent review, patients with a combination of components of manic and depressive state tend to experience more mood episodes and more functional impairment [10]. In addition, they are more likely to relapse, to have lower inter-episode intervals, to experience more rapid cycling, and to have higher rates of suicide and comorbid conditions, such as substance abuse [10]. Furthermore, it is recognized that mixed manic/depressive presentations in BD predicted poorer pharmacological response [11].

The onset of BD is generally from 15 to 35 years of age, but earlier onset is not infrequent. In older years, onset was held to be mostly in adult ages, but it has recently become clear that many more cases have their onset prior to the end of adolescence [12]. Accordingly, for BD-I patients, onset occurred at an age lower than 12 years of age in $5 \%$ of cases, between 13 and 17 years of age (adolescence) in $28 \%$ of cases, while $53 \%$ occurred during the age range between 15 and 25 years, when the onset of BD peaks [13]. Cases with adolescent and adult onset do not differ for many measures and outcomes, but childhood onset cases developed more episodes per year, had more family history of $\mathrm{BD}$, and displayed more psychiatric comorbidity than individuals with a later onset [13]. Furthermore, pooling together childhood and adolescent onset BD cases and compared to adult-onset patients, the former passed longer times with symptoms, displayed more polarity shifts, and showed more mixed symptoms [14]. With respect to adults with BD, in fact, children and adolescents are more likely to present with rapid cycling or to be in a mixed state [15]. Mixed states (or mixed features specifier) are a common occurrence in children and adolescents, not only in those diagnosed as having BD but also in those with a depressive episode. About $65 \%$ of a large sample with depression, either due to MDD or $\mathrm{BD}$, met mixed state criteria, compared to only about $35 \%$ of children and adolescents who had only depression [16]. In one study, about $40 \%$ of adolescents with depression had $\mathrm{BD}$ and, of these, $82 \%$ exhibited mixed states [17], prompting the authors to conclude that mixed states were the most common presentation in this age. These observations are in line with the clinical practice among childhood and adolescence psychiatrists but still await confirmation. We are not aware of a systematic review of mixed states literature in paediatric age, including data on associated clinical and psychopathological features and response to pharmacological treatment. This study aims to fill this gap by providing prevalence rates, comorbidity, and clinical presentations of mixed states/features in childhood and adolescence in order to inform clinicians of the available evidence regarding intervention strategies. 


\section{Materials and Methods}

\subsection{Search Strategy}

To investigate the epidemiology, features, and treatment response of mixed states/features in children and adolescents with BD, we conducted a PubMed search on 9 February 2021 using the following strategy: "mixed state *" AND (bipolar OR mood OR affect *) with the following filters applied: Humans, Child: birth-18 years, Newborn: birth-1 month, Infant: birth-23 months, Infant: 1-23 months, Child: 6-12 years, Adolescent: 13-18 years, Preschool Child: $2-5$ years.

\subsection{Eligibility and Study Selection}

Inclusion criteria included original studies in peer reviewed journals focusing on alive children and/or adolescents with BD and reporting data on mixed states/features as defined by various versions of the American Psychiatric Association (APA) DSM, beginning from the third edition. Eligible studies had to report original data on patients with mixed states regarding their prevalence, clinical course or psychopathology, or their response to treatment. Both longitudinal and cross-sectional studies were admitted and could be retrospective or prospective. There were no time limits or language limits in regard to the selection of appropriate studies.

Exclusion criteria: Studies were excluded if they repeated the same data (characterised as "same as other"); if they were conducted on adult patients (appearing despite filtering on PubMed and marked as "Adults" on the Preferred Reporting Items for Systematic Reviews and Meta-Analyses (PRISMA) flowchart); if they used both children and adult populations without specifying which symptoms referred to which population or if they pooled different diagnoses without specifically reporting mixed states in patients with BD (marked as "Lumping" on the PRISMA flowchart); if the study did not focus on (marked as "Unfocused" on the PRISMA flowchart) or was unrelated to the subject matter (to mark as "Unrelated" on the PRISMA flowchart); if the studies did not report data on mixed states (marked as "No mixed" on the PRISMA flowchart); or if they were animal studies (despite filtering, to mark as "Animal" on the PRISMA flowchart), surveys of clinicians about patient symptoms without an actual patient population (marked as "Survey" on the PRISMA flowchart), post mortem studies (marked as "Postmortem" on the PRISMA flowchart), case reports or series (marked as "Case" on the PRISMA flowchart), opinion papers such as editorials and letters to the editor (with no data, hypotheses, or observations on other published studies) (marked as "Opinion" on the PRISMA flowchart), and metaanalyses and reviews (marked as "Review" on the PRISMA flowchart). The latter were used to search among their references for possible further eligible studies.

All authors participated in the selection of eligible studies to include through Delphi rounds. Two rounds were sufficient to reach complete agreement. We adhered to the Preferred Reporting Items for Systematic Reviews and Meta-Analyses (PRISMA) Statement [18].

\subsection{Data Extraction and Synthesis}

The data of selected papers were extracted using a standardised spreadsheet. All authors introduced relevant data in the summary table and mutual comparison ensued on deciding which features to retain. The numbers of individuals with mixed features/mixed states were extracted from each study in order to provide prevalence rates, expressed as percentages.

\section{Results}

Our search PubMed strategy on the aforementioned date produced 96 records, which was added to another 5, obtained through alternative strategies, amounting to a grand total of 101 articles to assess. Eligible articles spanned from 1995 to 2015 . The inclusion process is highlighted in the PRISMA flowchart in Figure 1, which reports the reasons for exclusion. A summary of the included articles is displayed in Table 1. Of the included studies, five 
were longitudinal and six were cross-sectional. Three studies were interventional, and the others were observational. The eleven included studies involved a patient population of 1365 individuals, of whom $558(40.88 \%)$ were female and $807(59.12 \%)$ were male. Their age ranged from 3.5 to 20 years (we included two studies that comprised a few young adults with BD who had their onset during adolescence $[19,20])$. The prevalence rates of mixed features/mixed states in each study are reported in Figure 2. Overall, of the patients with paediatric age BD participating in eligible studies, 55.2\% had mixed states / features $(95 \%$ confidence intervals from 40.1 to 70.3 ). The clinical and psychopathological characteristics, and pharmacological treatment are reported in Table 1.

PRISMA 2009 Flow Diagram of search: "mixed state*" AND

(bipolar OR mood OR affect*) Filters applied: Humans, Child: birth-18 years, Newborn: birth-1 month, Infant: birth-23 months, Infant: 1-23 months, Child: 6-12 years, Adolescent: 13-18 years, Preschool Child: 2-5 years $\rightarrow$ PubMed 9-2-2021, 96 records +5 with alternative strategies
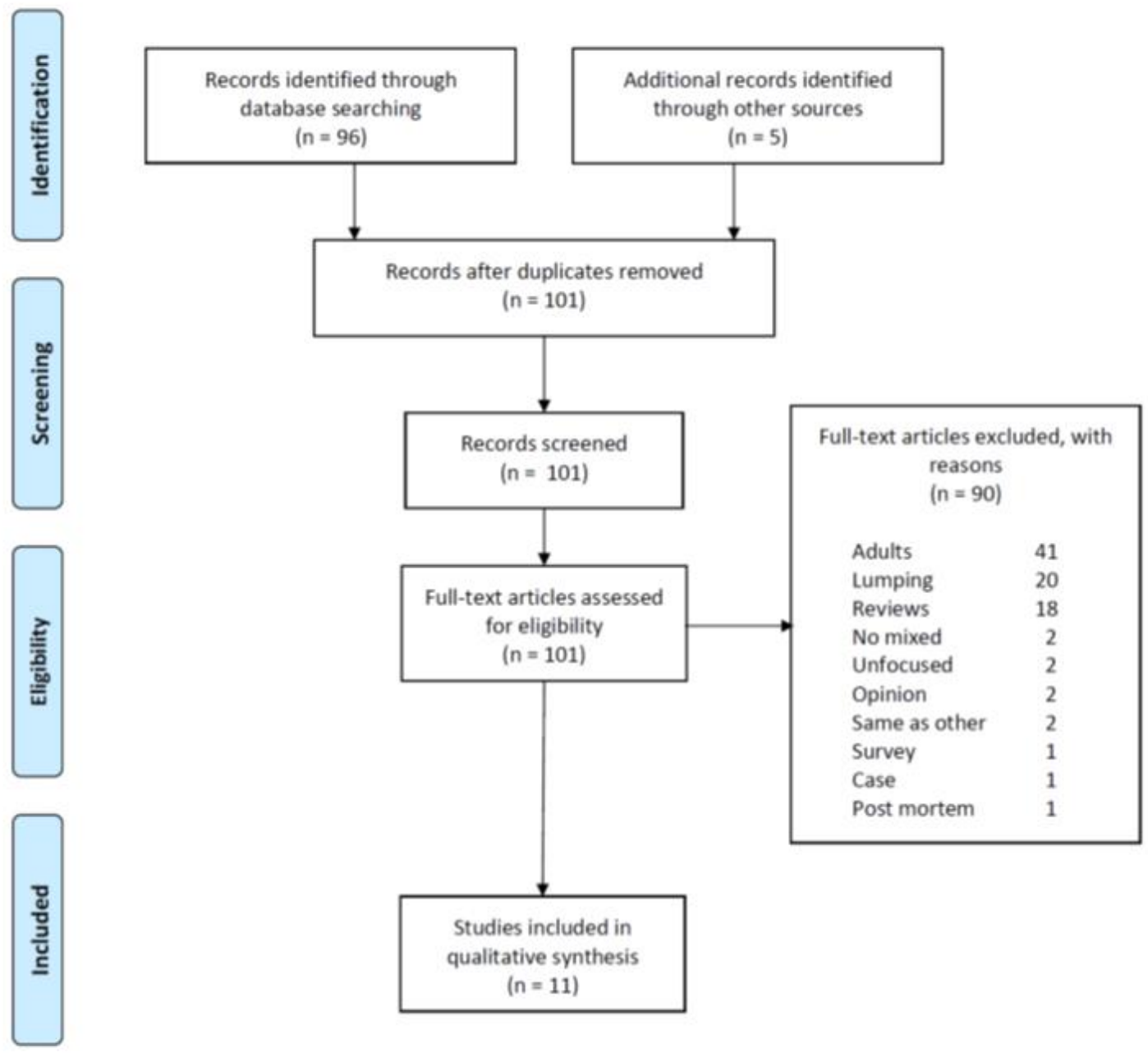

From: Moher D, Liberati A. Tetzlaff J, Altman DG, The PRISMA Group (2009). Preferred Reporting hems for Systematic Reviews and Meta. Analyses: The PRISMA Statement. PLOS Med 67): e 1000097. doi: 10. 1371/joumal pmed 1000097

For more information, visit www.prisma-statement.org.

Figure 1. Preferred Reporting Items for Systematic Reviews and Meta-Analyses (PRISMA) flow diagram of the inclusion strategy with exclusion reasons (after Moher et al., 2009 [18]). 


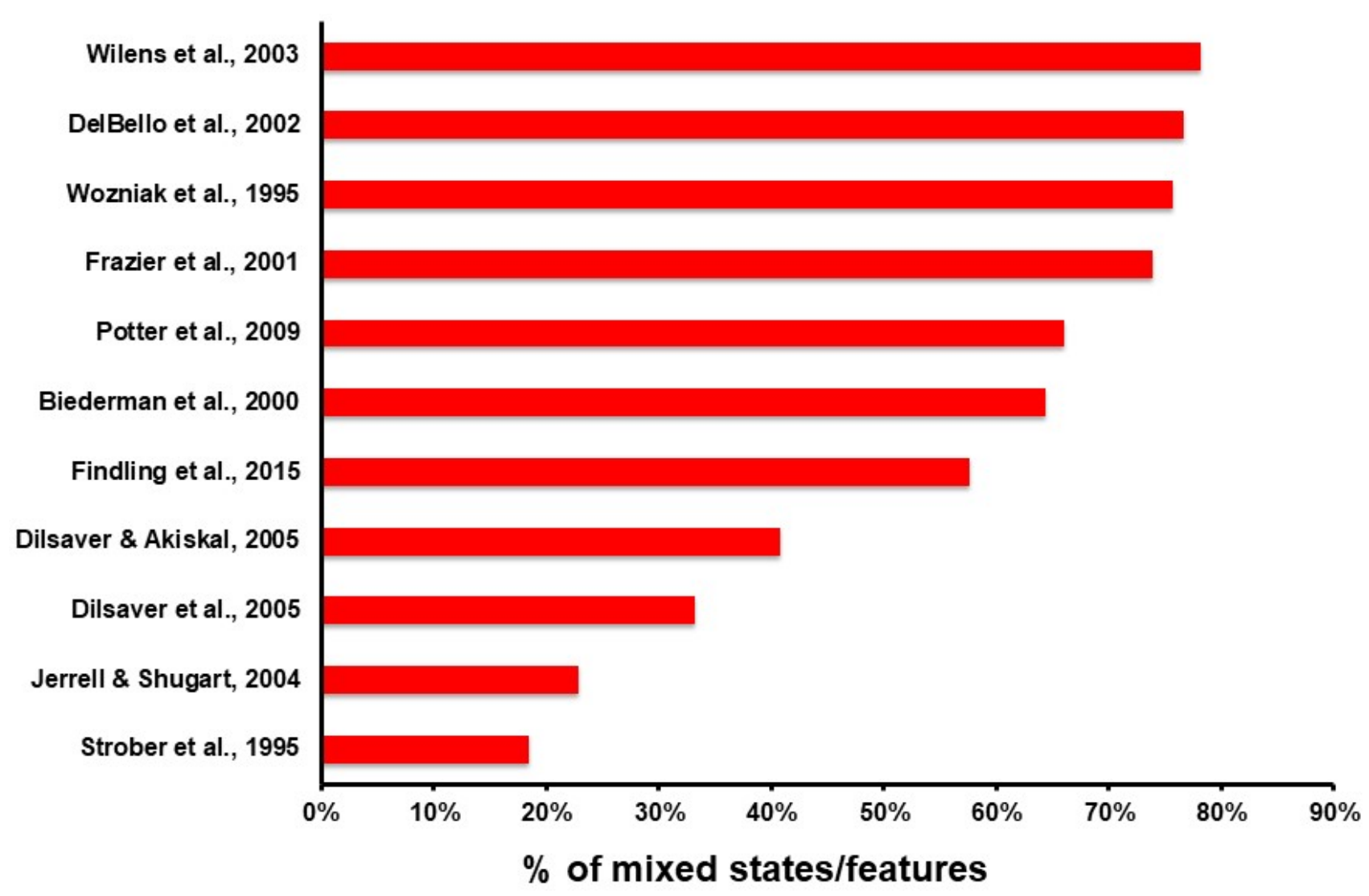

Figure 2. Prevalence rates of mixed features/mixed states in the included studies, from higher (top) to lower (bottom) $[15,19-28]$.

Comorbidities in the entire sample were variable and dependent on the authors' main focuses. In the first eligible study [25], comorbidity with substance use was observed in $22 \%$ of cases during the 5-year follow-up. In another cross-sectional study [26], comorbidity rates were high, although not specified in patients showing mixed symptoms but in the entire sample without ADHD (oppositional defiant disorder, $88 \%$; past major depressive episodes, $86 \%$; at least two anxiety disorders, $44 \%$; conduct disorder, $37 \%$; and tic disorders, $26 \%$ ). Similar high-comorbidity results were reported by another study, i.e., oppositional defiant disorder, 100\%; attention deficit/hyperactivity disorder (ADHD), 78\%; phobia, 57\%; separation anxiety disorder, $52 \%$; overanxious disorder, $48 \%$; conduct disorder, $35 \%$; and obsessive-compulsive disorder, 35\% [22], and still another of the same time period, which reported comorbidities approaching $100 \%$ of $\mathrm{BD}$ with $\mathrm{ADHD}$ and with $70 \%$ comorbidity with any anxiety disorder [29]. Another study, relying on symptoms appearing in medical records, reported in their BD sample $42 \%$ ADHD, 30\% schizophrenia, $25 \%$ conduct disorder, and $18 \%$ PTSD [19]. However, BD-schizophrenia cooccurrence is unlikely and the results of this study must be interpreted with caution. Another study focused on only BDADHD comorbidity, reporting it to be $54.6 \%$, with $24 \%$ of patients making use of stimulant medications [23], while another that examined multiple comorbidities found ADHD to cooccur with ADHD in $60 \%$ of cases, of which $13 \%$ had cooccurrence of ADHD, depression, and anxiety [20]. Other studies reported no comorbidity at all [15,21,24,28], although recognising BD-ADHD comorbidity to be an issue and to affect treatment strategies [21]. 
Table 1. Summary of the 11 eligible studies included in this review in order of year of publication.

\section{Study}

Design/Clinical Assessment

Population

LS; 5-yr follow-up; clinical observation

Strober et al., 1995 [25], Los Angeles, CA RDC (a predecessor of the DSM-II

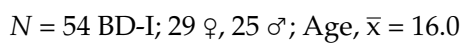
years; range $13-17$ years $N=262$ referrals for outpatient whom 207 had either mania $(N=43$, age $\overline{\mathrm{x}}=7.9 \pm 2.6$ years; $36 \sigma^{7}, 7$ \%) or ADHD $\left(N=164\right.$, age $\bar{x}=8.8 \pm 2.2$ years; $1410^{7}$ 23 )); compared with 84 non-ADHD controls (age $\bar{x}=9.0 \pm 2.1$ years; $710^{7}, 13$

१); age, $<12$ DSM-III-R

$N=59$ referrals for outpatient

Biederman et al., 2000 [21], Boston, MA

LS, RChR; effect of treatments; DSM-III-R, K-SADS-E $\operatorname{BD}\left(490^{7}, 10\right.$ o : Age, $\bar{x}=10.8+3.7$ wears range $3.5-17$ years)

\section{Results}

On admission, 20 were manic, 14 were epressed, 10 were mixed, and 10 were cycling: manic or mixed presentation cycling m 11 weeks, 11 respectively, whereas depressive recoverd in a whereas depressive recovered in a median time of 26 weeks and rapid
cycling recovered in 15 weeks

Of children with mania, $14 \%(N=6)$ had mania only, $84 \%(N=36)$ had a mixed presentation, and $2 \%(N=1)$ had nonoverlapping episodes of mania and mixed episodes $(84 \%)$

The occurrence of mixed episodes was frequent in the sample. The patients frequent in the sample. The patients received TCAs (45\%), stimulants (20\%), SSRIs $(20 \%)$, mood stabilisers $(40 \%)$, or GAs $(10 \%)$ during their follow-up visit Depression was more responsive to SSRIs than to other treatments

This study supports the use of antidepressant monotherapy in youth with mixed states. The study was times, SSRIs were not completely introduced in the US market. This justifies the lower rate of SSRI conducted during 1991-1995; at those prescription compared to TCAs.

Improvement criteria: at least 30\% drop of YMRS score from baseline levels plus maximum 3 on the CGI-S mania, $61 \%$ responder rate; 17 patients $(74 \%$ ) with mixed presentation

$\mathrm{S} ; 20 \mathrm{mg} / \mathrm{d}$ open-label olanzapine $\times$ eeks at 1 site; DSM-IV; assessment

23 BD-I and -II (manic, mixed, or hypomanic; age, $\bar{x}=10.3 \pm 2.9$ years, range 5-14 years; $130^{7}, 10$ ㅇ)

30 BD-I patients with manic or mixed

episodes randomised to valproate + quetiapine $(N=15$; age,

DelBello et al, 2002 [15] Cincinnati, OH valproate; random allocation $\times 6$ weeks, double-blind, parallel; DSM-IV; YMRS primary outcome $\bar{x}=14.1 \pm 2$ years; $80^{7}, 7$ \%) or valproate t placebo $(N=15$; age, $\bar{x}=14.5$ years $\pm 2 i$ $80^{7}, 7$ \%)
$3(87 \%)$ of patients randomised to valproate + placebo and $10(67 \%)$ to valproate + quetiapine. Valproate + quetiapine reduced YMRS significantly

better than valproate + placebo (but 7 patients in the former group quit the study before endpoint)
No reported differential response for patients with mixed symptoms

High attrition rate in the valproate + quetiapine group through LOCF. No differe provid LOCF. No differential data patients. Small sample size 
Table 1. Cont.

Study

$\mathrm{CS}$, RChR; included if meeting DSM-III-R criteria. Assessed with

K-SADS-E preschoolers 4-6-yr-old

Wilens et al., 2003 [27], Boston, MA refred to a psychopharmacology clinic

for $\mathrm{BD}$ and $\mathrm{BD}$ probands 7-9-yr-old

$\mathrm{CS}, \mathrm{RChR}$; utilised a cross-nationa database of clinical records of children with various psychopathological disorders diagnosed with the DSM-IV

Jerrell \& Shugart, 2004 [19], USA
Dilsaver \& Akiskal, 2005 [28], Merced CA
CS; assessment with SCID-DSM-IV of adolescents referred for MDD (MDE present)
49 consecutive Hispanic adolescents (age range $23-27$ years; 33 owith age $\bar{x}=14.8$ \pm 1.6 years, $160^{7}$ with age $\bar{x}=14.8 \pm 1.8$ years)
Dilsaver et al, 2005 [24], Merced, CA
CS; acreening adolescent Hispanic (99\%) destitues for mixed states with the SCID-DSM-IV
Identified 83 patients with $\mathrm{BD}$ (age, $\bar{x}=$ 5 years; $430^{7}, 40$ ) $)$; 16 were aged $7-12$ years, 67 were 13 -20-years-old
44 preschoolers with $\mathrm{BD}$ (age, $\bar{x}=5.1 \pm$ 0.8 years; $350^{7}, 9$ \%) $29 \mathrm{BD}$ probands (age, $\bar{x}=7.8 \pm 0.9$ years; $\left.24 \circ^{7}, 5 \circ\right)$
247 adolescents with MDE screened for mixed states (age $\bar{x}=14.7 \pm 1.5$ years; range, 12-17 years; $1080^{7}, 139$ \%)

\section{Results}

The two samples did not differ for psychopathology, other than conduct disorders, largely explained by oppositive-defiant disorder; $80 \%$ of reschoolers and $76 \%$ of school-ag probands had mixed episodes

Most patients shared ADHD and conduct disorder symptoms; the two age groups did not differ in symptoms, save or the fact that very early onset childre were more distractible, excitable, irritable, and fidgety and that early onse $\mathrm{BD}$ children displayed more depression

$$
23 \% \text { had mixed episodes }
$$

Most patients were rediagnosed; $55 \%$ BD, 8.2\% BD-I, 6.1\% BD-II, and 40.9\% mixed state. Half of the osample had family history positive for mood disorder and about one fourth had family history positive for MDD; 17 (51.5\%) Oand 10 (62.5\%) $0^{7}$ met DSM-IV (51.5\%) Pand $162.5 \%$ ) met DSM-IV criteria for BD. Psych tic features were more present in MDD than BD girls; the opposite was true for boys; irritability was shared by about $80 \%$ of the sample and hostility by about $50 \%$

100 patients were with $\mathrm{BD}(40.5 \%)$; of them, 82 had a mixed state $\left(460^{7}, 36\right.$ \% $33.1 \%$ of the whole sample); 147 met MDD criteria; 99 displayed psychotic features; 164 had suicidal ideation, 118 had past suicide attempts; $101 \mathrm{had}$ positive family history for mood disorders (57 MDD, 44 BD). Only 11 were purely depressive BD-I and 7

\section{Conclusions}

Children 4-6-year-old and those of 7-9 years of age with BD share

psychopathological features and report similar rates of mixed states

About one fourth of patients with preadolescent and adolescent paediatric $B D$ have mixed symptoms; in both high

rates of ADHD and conduct disorder comorbidity

Most adolescents have more mixed states than pure depressive or manic/hypomanic presentations during a MDE. More than $40 \%$ of Hispanic adolescents present with mixed episodes,

in line with results of other adolescent populations

Confirmed was the high occurrence of mixed states in the presentation of adolescent patients with $\mathrm{BD}$; the nonmixed samples did not differ from the mixed one for suicidal ideation or suicidal attempts 
Table 1. Cont.

Study

CS, RChR; youths diagnosed with DSM-IV BD at a paediatric

Potter et al., 2009 [20], Boston, MA psychopharmacology clinic; assessed severity according to treatment received responder was a patient with CGI-I 1 or 2

LS; double-blind randomised 1:1:1:1 assignment to 5,10 , and $20 \mathrm{mg} /$ day assigna

Findling et al., 2015 [23], multicentre (76 US; 10 Russia)
(DSM-IV-R)

YMRS, CGI-BP; responder: who dropped $\geq 50 \%$ on the YMRS from baseline

\section{Population}

$53($ age, $\bar{x}=13 \pm 3.6$ years, range $4-19$

ears: $18(34 \%)<12$-year-old, $39(74 \%) 0^{7}$ $14(26 \%)$ \%)

03 patients (age, $\bar{x}=13.8+2.0212$; range, $10-17$ years; $9(52.6 \%))$ with mani $(N=171)$ or mixed state $(N=232)$

randomised to placebo $(N=101), 5 \mathrm{mg}$ $(N=104), 10 \mathrm{mg}(N=99)$, or $20 \mathrm{mg}$ asenapine $(N=99)$

\section{Results}

Treated for comorbidity, 32 (68\%); for ADHD, $32(60 \%)$; for depression, 18 $(34 \%)$; and for anxiety, $14(26 \%)$.

Monotherapy in $23 \%$ of patients, mostly SGAs. Responder rates, $80 \%$ o $57 \%$ of mixed states, $56 \%$ of ADHD, $61 \%$
of anxiety, and $90 \%$ of depression

ADHD comorbidity $N=220(54.6 \%)$ total comorbidities, $N=256(63.5 \%)$, with stimulant use $N=96(23.8 \%)$; asenapine performed better than placebo (lower and higher dosages, but all doses were equally efficacious on the CGI-BP). Responder rates, 42-54\% with asenapine, $28 \%$ with placebo

\section{Conclusions}

Provided response for mixed state but pooled numbers of patients with mania with those with mixed state. Results how mania to be a more unstable state than the mixed and a more responsive to SGAs

Mixed states still constitute the majority of $\mathrm{BD}$ presentations in children and adolescents; more than one fourth of adolescents; more than one fourth of
patients are likely to respond to placebo at the 3-week endpoint. Site effects analysed but not reported; separate analyses carried out for ADHD comorbidity (with or without) but not for pure mania vs. mixed state responsiveness

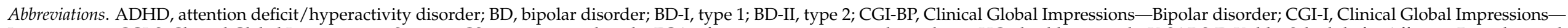

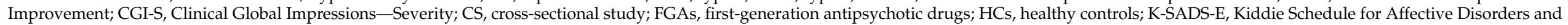

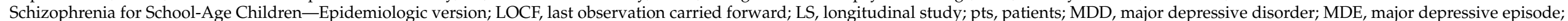

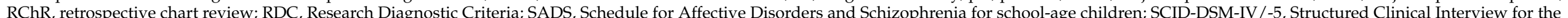

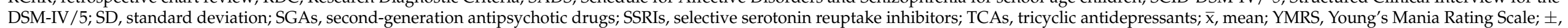
$\mathrm{SD} ;$ , female; $\sigma^{\natural}$, male. 


\section{Discussion}

In this systematic review, we confirmed what has always been a common impression among clinicians, i.e., that mixed states are frequent in children and adolescents. We found, in fact, that $55.2 \%$ of young individuals with BD presented with mixed states/features. This means that at least half of paediatric patients with BD experienced symptoms of the opposite polarity during mania/depression.

Why are mixed states/features so common in children and adolescents? One factor that may underpin this high prevalence could be emotional dysregulation. Emotion dysregulation is defined by difficulties in monitoring and evaluating emotional experiences, in modulating their intensity or duration, and in adaptively managing emotional reactions [30]. High levels of emotional dysregulation have been reported in adolescence [31] and may be explained by neurobiological substrates. It should be stated, in fact, that children and adolescents are in a condition of continuous brain maturation, which contributes to their being emotionally labile [32,33]., Emotional lability may depend on changes in subcortical structures, particularly in the limbic system [34], which has been reported as biomarkers of BD [35]. Specifically, emotional lability is a feature of BD and it has also been highlighted as a core feature of mixed states [36,37]. Interestingly, recent investigations found that the effect of BD diagnosis on subcortical structures, in particular limbic areas involved in emotion regulation, was mediated by traumatic events occurring during childhood [38,39]. Accordingly, a recent study hypothesised that childhood trauma could be related to the development of mixed states thought the mediation effect of emotional dysregulation /emotional lability [40].

In terms of clinical presentation, in this study, we found in children with mixed states/features high rates of comorbidities with other psychiatric disorders typical of the paediatric age. In particular, the largest agreement among the included studies was in reporting high rates of attention deficit hyperactivity disorder (ADHD), oppositional defiant disorder, and anxiety disorders. Anxiety disorders and BD are often comorbid and share genetic risk factors [41]. In particular, a recent study found that comorbid anxiety disorders reflect a dual burden of BD and anxiety-related genes [41]. Furthermore, anxiety disorder comorbidity adversely impacts the clinical course of the disease [42] and a recent meta-analysis confirmed that they are highly comorbid not only with adult but also with paediatric BD [43]. Oppositional defiant disorder and conduct disorder are very typically diagnoses of children and adolescents. They refer not only to the mood alterations that define BD but also to the behavioural alterations that may be encountered in social interactions. Nevertheless, it is well recognized that oppositional defiant disorder and BD and are highly comorbid. In particular, oppositional defiant disorder comorbidity has been predominantly demonstrated in patients with cooccurring BD and ADHD [44]. ADHD is also often encountered in comorbidity with BD in the adult age, although adult ADHD is often overlooked by adult psychiatrists when other explanations of the patient's clinical status are available. Comorbid ADHD is present in up to $58.6 \%$ of paediatric patients with $\mathrm{BD}$ [45], while in children and adolescents with ADHD, the cooccurrence with bipolar disorder is $22 \%$ [46]. Interestingly, emotional dysregulation/lability is a core symptom of both paediatric and adult ADHD [47] and a predictor of adult emotional lability [48]. Therefore, it is possible that similar neurodevelopmental alterations result in abnormal neuronal firing in both BD and ADHD, which both display emotional lability. This hypothesis supports the more general concept that psychiatric disorders could share common neurobiological substrates, including neural activity [49] and connectivity patterns [50].

Available evidences regarding the treatment of mixed states/features in BD are currently insufficient to draw conclusions in our systematic review. Of the 11 eligible studies, five dealt with the effects of pharmacotherapy, but of these, two were observational, two were open label, and only one was double blind. The two observational studies assessed the effects of ongoing drug treatment, both considering a similar broad spectrum of drugs from mood stabilisers to antidepressants, stimulants, and antipsychotics [20,21]. Of the experimental studies, all used second-generation antipsychotics; the two open-label studies 
used $20 \mathrm{mg}$ /day olanzapine [22] and $450 \mathrm{mg}$ /day quetiapine as add-on to valproate [15], while the only double-blind study used $20 \mathrm{mg} /$ day asenapine [23], the maximum dose for children. Only the latter was based on a relatively large sample. None of these drugs showed higher or lower efficacy in mixed states. It is surprising that, despite the high frequency of mixed states/features in children and adolescents, few studies have addressed the issue of their pharmacological treatment. One reason could be that the field of child and adolescent psychopharmacology is relatively new, and another is that there are fewer treatments approved for paediatric use than for adults. Another reason could be that psychiatrists in childhood, such as in the adult age [8], tend to primarily consider mania and depression [51] rather than focus on mixed features. Future studies should focus on mixed states and pharmacological treatment and, in particular, on treatment response to lithium, which is considered the goal standard among mood stabilizers and is associated with changes in subcortical structures [52].

A similar uncertainty is seen in psychopathological issues. Although the scientific community is increasingly endeavouring in mixed state/features matters, there is still insufficient focus on psychopathological features. None of the studies considered in this review addressed specific dimensions, such as irritability, agitation, anhedonia, and impulsiveness, which have extensively been described in mixed states [53]. Similarly, little attention has been paid to suicidal risk. It is important to rate mixed symptoms in paediatric patients with $\mathrm{BD}$, since suicidal ideation and behaviours are not infrequent in childhood [29] and mixed features are associated with increased risk of suicide in BD [54]. However, in the only included study that focused on suicide ideation and attempts [24], no differences were reported in both measures between mixed and non-mixed symptom patients. Furthermore, an important issue is the possible diagnostic confusion between mixed features/states and rapid cycling. Although this point has been focused on in the various DSM versions, mixed states and rapid cycling showed potential clinical overlap [55]. This could be partly related to a common pattern of "mood instability", which may involve both the coexistence of mania and depression and a pattern of frequent mood episodes. Accordingly, there is a need for further investigation in this particular field in order to demarcate features of mixed state and rapid cycling during psychiatric assessment in BD.

Limitations. Our review has the limitation of the small number of included studies and the small sample sizes that most of them employed. The methodologies were heterogeneous and sometimes unfocused, thus leaving out important questions, such as individual symptoms of mixed states/features. Another limitation that led us to exclude many studies was that studies tended to include patients with mixed or manic states without diversifying them, a pitfall carried on from adult psychiatry. Included studies used three different versions of the DSM, with DSM-III and DSM-IV radically differing in their views of mixed states from the DSM-5. This heterogeneity did not allow any meta-analysis of the results.

\section{Conclusions}

Summarising the evidence we obtained from the literature, mixed states are extremely frequent in children and adolescents. Nevertheless, methodologies in assessing them are heterogeneous and future studies are needed to corroborate diagnosis consistency. Furthermore, mixed states are characterised by high rates of comorbidity with typical paediatric psychiatric disorders, in particular, ADHD. The response to pharmacological treatment and the role of psychopathological dimensions have not been focused upon much in this specific literature, thus pointing to future investigational targets. In conclusion, mixed states need to be assessed in childhood and considered as a core feature of paediatric $\mathrm{BD}$ in direct opposition to the idea that mood disorders only swing from depression to mania. 
Funding: This manuscript received no funding.

Acknowledgments: We thank our secretary Paolo Croce for the observations and support during the writing of this manuscript.

Conflicts of Interest: The authors declare no conflict of interest.

\section{References}

1. Kraepelin, E. Psychiatrie: Ein Lehrbuch für Studirende und Aerzte; Verlag von Johann Ambrosius Barth: Leipzig, Germany, 1899.

2. Weygandt, W. Über die Mischzustände des Manisch-Depressiven Irreseins: Ein Beitrag zur Klinischen Psychiatrie; J. F. Lehmann: Munich, Germany, 1899.

3. Cassano, G.B.; Micheli, C. Psychotic mixed states. Clin. Neuropharmacol. 1992, 15. [CrossRef]

4. Koukopoulos, A.; Faedda, G.; Proietti, R.; D’Amico, S.; de Pisa, E.; Simonetto, C. Mixed depressive syndrome. L'Encéphale 1992, 18, 19-21. [CrossRef]

5. Perugi, G.; Akiskal, H.S.; Micheli, C.; Musetti, L.; Paiano, A.; Quilici, C.; Rossi, L.; Cassano, G.B. Clinical subtypes of bipolar mixed states: Validating a broader European definition in 143 cases. J. Affect. Disord. 1997, 43, 169-180. [CrossRef]

6. Akiskal, H.S. The distinctive mixed states of bipolar I, II, and III. Clin. Neuropharmacol. 1992, 15. [CrossRef] [PubMed]

7. Koukopoulos, A.; Sani, G.; Koukopoulos, A.E.; Manfredi, G.; Pacchiarotti, I.; Girardi, P. Melancholia agitata and mixed depression. Acta Psychiatr. Scand. 2007, 115, 50-57. [CrossRef] [PubMed]

8. Koukopoulos, A.; Sani, G. DSM-5 criteria for depression with mixed features: A farewell to mixed depression. Acta Psychiatr. Scand. 2014, 129, 4-16. [CrossRef]

9. Pacchiarotti, I.; Nivoli, A.M.A.; Mazzarini, L.; Kotzalidis, G.D.; Sani, G.; Koukopoulos, A.; Scott, J.; Strejilevich, S.; SánchezMoreno, J.; Murru, A.; et al. The symptom structure of bipolar acute episodes: In search for the mixing link. J. Affect. Disord. 2013, 149, 56-66. [CrossRef]

10. Vieta, E.; Valentì, M. Mixed states in DSM-5: Implications for clinical care, education, and research. J. Affect. Disord. 2013, 148, 28-36. [CrossRef]

11. Yildiz, A.; Vieta, E.; Tohen, M.; Baldessarini, R.J. Factors modifying drug and placebo responses in randomized trials for bipolar mania. Int. J. Neuropsychopharmacol. 2011, 14, 863-875. [CrossRef]

12. Dagani, J.; Baldessarini, R.J.; Signorini, G.; Nielssen, O.; de Girolamo, G.; Large, M. The age of onset of bipolar disorders. In Age of Onset of Mental Disorders; Springer: Cham, Switzerland, 2019; pp. 75-110. ISBN 9783319726199.

13. Baldessarini, R.J.; Tondo, L.; Vázquez, G.H.; Undurraga, J.; Bolzani, L.; Yildiz, A.; Khalsa, H.M.K.; Lai, M.; Lepri, B.; Lolich, M.; et al. Age at onset versus family history and clinical outcomes in 1665 international bipolar-I disorder patients. World Psychiatry 2012, 11, 40-46. [CrossRef]

14. Goldstein, B.I.; Birmaher, B. Prevalence, clinical presentation and differential diagnosis of pediatric bipolar disorder. Isr. J. Psychiatry Relat. Sci. 2012, 49, 3-14.

15. DelBello, M.P.; Schwiers, M.L.; Rosenberg, H.L.; Strakowski, S.M. A double-blind, randomized, placebo-controlled study of quetiapine as adjunctive treatment for adolescent mania. J. Am. Acad. Child. Adolesc. Psychiatry 2002, 41, 1216-1223. [CrossRef]

16. Frazier, E.A.; Swenson, L.P.; Mullare, T.; Dickstein, D.P.; Hunt, J.I. Depression with mixed features in adolescent psychiatric patients. Child. Psychiatry Hum. Dev. 2017, 48, 393-399. [CrossRef] [PubMed]

17. Dilsaver, S.C.; Benazzi, F.; Akiskal, H.S. Mixed states: The most common outpatient presentation of bipolar depressed adolescents? Psychopathology 2005, 38, 268-272. [CrossRef]

18. Moher, D.; Liberati, A.; Tetzlaff, J.; Altman, D. Preferred reporting items for systematic reviews and meta-analyses: The prisma statement. BMJ 2009, 339, b2535. [CrossRef] [PubMed]

19. Jerrell, J.M.; Shugart, M.A. Community-based care for youths with early and very-early onset bipolar I disorder. Bipolar Disord. 2004, 6, 299-304. [CrossRef] [PubMed]

20. Potter, M.P.; Liu, H.Y.; Monuteaux, M.C.; Henderson, C.S.; Wozniak, J.; Wilens, T.E.; Biederman, J. Prescribing patterns for treatment of pediatric bipolar disorder in a specialty clinic. J. Child. Adolesc. Psychopharmacol. 2009, 19, 529-538. [CrossRef]

21. Biederman, J.; Mick, E.; Spencer, T.J.; Wilens, T.E.; Faraone, S.V. Therapeutic dilemmas in the pharmacotherapy of bipolar depression in the young. J. Child. Adolesc. Psychopharmacol. 2000, 10, 185-192. [CrossRef]

22. Frazier, J.A.; Biederman, J.; Tohen, M.; Feldman, P.D.; Jacobs, T.G.; Toma, V.; Rater, M.A.; Tarazi, R.A.; Kim, G.S.; Garfield, S.B.; et al. A prospective open-label treatment trial of olanzapine monotherapy in children and adolescents with bipolar disorder. J. Child. Adolesc. Psychopharmacol. 2001, 11, 239-250. [CrossRef]

23. Findling, R.L.; Landbloom, R.L.; Szegedi, A.; Koppenhaver, J.; Braat, S.; Zhu, Q.; Mackle, M.; Chang, K.; Mathews, M. Asenapine for the acute treatment of pediatric manic or mixed episode of bipolar I disorder. J. Am. Acad. Child. Adolesc. Psychiatry 2015, 54, 1032-1041. [CrossRef]

24. Dilsaver, S.C.; Benazzi, F.; Rihmer, Z.; Akiskal, K.K.; Akiskal, H.S. Gender, suicidality and bipolar mixed states in adolescents. J. Affect. Disord. 2005, 87, 11-16. [CrossRef]

25. Strober, M.; Schmidt-Lackner, S.; Freeman, R.; Bower, S.; Lampert, C.; DeAntonio, M. Recovery and relapse in adolescents with bipolar affective illness: A five-year naturalistic, prospective follow-up. J. Am. Acad. Child. Adolesc. Psychiatry 1995, 34, 724-731. [CrossRef] 
26. Wozniak, J.; Biederman, J.; Kiely, K.; Ablon, J.S.; Faraone, S.V.; Mundy, E.; Mennin, D. Mania-like symptoms suggestive of childhood-onset bipolar disorder in clinically referred children. J. Am. Acad. Child. Adolesc. Psychiatry 1995, 34, 867-876. [CrossRef]

27. Wilens, T.E.; Biederman, J.; Forkner, P.; Ditterline, J.; Morris, M.; Moore, H.; Galdo, M.; Spencer, T.J.; Wozniak, J. Patterns of comorbidity and dysfunction in clinically referred preschool and school-age children with bipolar disorder. J. Child. Adolesc. Psychopharmacol. 2003, 13, 495-505. [CrossRef]

28. Dilsaver, S.C.; Akiskal, H.S. High rate of unrecognized bipolar mixed states among destitute Hispanic adolescents referred for "major depressive disorder". J. Affect. Disord. 2005, 84, 179-186. [CrossRef]

29. Janiri, D.; Doucet, G.E.; Pompili, M.; Sani, G.; Luna, B.; Brent, D.A.; Frangou, S. Risk and protective factors for childhood suicidality: A US population-based study. Lancet Psychiatry 2020, 7, 317-326. [CrossRef]

30. Gratz, K.L.; Roemer, L. Multidimensional assessment of emotion regulation and dysregulation: Development, factor structure, and initial validation of the difficulties in emotion regulation scale. J. Psychopathol. Behav. Assess. 2004, 26, 41-54. [CrossRef]

31. Silvers, J.A.; McRae, K.; Gabrieli, J.D.E.; Gross, J.J.; Remy, K.A.; Ochsner, K.N. Age-related differences in emotional reactivity, regulation, and rejection sensitivity in adolescence. Emotion 2012, 12, 1235-1247. [CrossRef]

32. Hare, T.A.; Tottenham, N.; Galvan, A.; Voss, H.U.; Glover, G.H.; Casey, B.J. Biological substrates of emotional reactivity and regulation in adolescence during an emotional go-nogo task. Biol. Psychiatry 2008, 63, 927-934. [CrossRef]

33. Veroude, K.; Jolles, J.; Croiset, G.; Krabbendam, L. Changes in neural mechanisms of cognitive control during the transition from late adolescence to young adulthood. Dev. Cogn. Neurosci. 2013, 5, 63-70. [CrossRef]

34. Hulvershorn, L.A.; Mennes, M.; Castellanos, F.X.; di Martino, A.; Milham, M.P.; Hummer, T.A.; Roy, A.K. Abnormal amygdala functional connectivity associated with emotional lability in children with attention-deficit/hyperactivity disorder. J. Am. Acad. Child. Adolesc. Psychiatry 2014, 53, 351-361. [CrossRef]

35. Hibar, D.P.; Westlye, L.T.; van Erp, T.G.M.; Rasmussen, J.; Leonardo, C.D.; Faskowitz, J.; Haukvik, U.K.; Hartberg, C.B.; Doan, N.T.; Agartz, I.; et al. Subcortical volumetric abnormalities in bipolar disorder. Mol. Psychiatry 2016, 21, 1710-1716. [CrossRef]

36. Brancati, G.E.; Vieta, E.; Azorin, J.-M.; Angst, J.; Bowden, C.L.; Mosolov, S.; Young, A.H.; Perugi, G. The role of overlapping excitatory symptoms in major depression: Are they relevant for the diagnosis of mixed state? J. Psychiatr. Res. 2019, 115, 151-157. [CrossRef]

37. Perugi, G.; Pacchiarotti, I.; Mainardi, C.; Verdolini, N.; Menculini, G.; Barbuti, M.; Angst, J.; Azorin, J.-M.; Bowden, C.L.; Mosolov, S.; et al. Patterns of response to antidepressants in major depressive disorder: Drug resistance or worsening of depression are associated with a bipolar diathesis. Eur. Neuropsychopharmacol. 2019, 29, 825-834. [CrossRef]

38. Janiri, D.; Sani, G.; de Rossi, P.; Piras, F.; Iorio, M.; Banaj, N.; Giuseppin, G.; Spinazzola, E.; Maggiora, M.; Ambrosi, E.; et al. Amygdala and hippocampus volumes are differently affected by childhood trauma in patients with bipolar disorders and healthy controls. Bipolar Disord. 2017, 19, 353-362. [CrossRef]

39. Janiri, D.; Sani, G.; de Rossi, P.; Piras, F.; Banaj, N.; Ciullo, V.; Simonetti, A.; Arciniegas, D.B.; Spalletta, G. Hippocampal subfield volumes and childhood trauma in bipolar disorders. J. Affect. Disord. 2019, 253, 35-43. [CrossRef]

40. Janiri, D.; Kotzalidis, G.D.; de Chiara, L.; Koukopoulos, A.E.; Aas, M.; Sani, G. The ring of fire: Childhood trauma, emotional reactivity, and mixed states in mood disorders. Psychiatr. Clin. N. Am. 2020, 43, 69-82. [CrossRef]

41. Bipolar Genome Study Consortium (BiGS). Polygenic risk for anxiety influences anxiety comorbidity and suicidal behavior in bipolar disorder. Transl. Psychiatry 2020, 10, 298. [CrossRef]

42. Spoorthy, M.S.; Chakrabarti, S.; Grover, S. Comorbidity of bipolar and anxiety disorders: An overview of trends in research. World J. Psychiatry 2019, 9, 7-29. [CrossRef]

43. Yapıcı Eser, H.; Taşkıran, A.S.; Ertınmaz, B.; Mutluer, T.; Kılıç, Ö.; Özcan Morey, A.; Necef, I.; Yalçınay İnan, M.; Öngür, D. Anxiety disorders comorbidity in pediatric bipolar disorder: A meta-analysis and meta-regression study. Acta Psychiatr. Scand. 2020, 141, 327-339. [CrossRef]

44. Masi, G.; Perugi, G.; Toni, C.; Millepiedi, S.; Mucci, M.; Bertini, N.; Pfanner, C. Attention-deficit hyperactivity disorder-Bipolar comorbidity in children and adolescents. Bipolar Disord. 2006, 8, 373-381. [CrossRef]

45. Hassan, A.; Agha, S.S.; Langley, K.; Thapar, A. Prevalence of bipolar disorder in children and adolescents with attention-deficit hyperactivity disorder. Br. J. Psychiatry 2011, 198, 195-198. [CrossRef]

46. Biederman, J.; Faraone, S.; Mick, E.; Wozniak, J.; Chen, L.; Ouellette, C.; Marks, A.; Moore, P.; Garcia, J.; Mennin, D.; et al. Attention-deficit hyperactivity disorder and juvenile mania: An overlooked comorbidity? J. Am. Acad. Child. Adolesc. Psychiatry 1996, 35, 997-1008. [CrossRef]

47. Maire, J.; Galera, C.; Bioulac, S.; Bouvard, M.; Michel, G. Emotional lability and irritability have specific associations with symptomatology in children with attention deficit hyperactivity disorder. Psychiatry Res. 2020, 285, 112789. [CrossRef]

48. Gisbert, L.; Richarte, V.; Corrales, M.; Ibáñez, P.; Bosch, R.; Casas, M.; Ramos-Quiroga, J.A. The impact of emotional lability symptoms during childhood in adults with ADHD. J. Atten. Disord. 2018, 22, 581-590. [CrossRef]

49. Janiri, D.; Moser, D.A.; Doucet, G.E.; Luber, M.J.; Rasgon, A.; Lee, W.H.; Murrough, J.W.; Sani, G.; Eickhoff, S.B.; Frangou, S. Shared neural phenotypes for mood and anxiety disorders: A meta-analysis of 226 task-related functional imaging studies. JAMA Psychiatry 2020, 77, 172-179. [CrossRef] 
50. Doucet, G.E.; Janiri, D.; Howard, R.; O’Brien, M.; Andrews-Hanna, J.R.; Frangou, S. Transdiagnostic and disease-specific abnormalities in the default-mode network hubs in psychiatric disorders: A meta-analysis of resting-state functional imaging studies. Eur. Psychiatry 2020, 63, e57. [CrossRef]

51. Janiri, D.; di Nicola, M.; Martinotti, G.; Janiri, L. Who's the leader, mania or depression? Predominant polarity and alcohol/polysubstance use in bipolar disorders. Curr. Neuropharmacol. 2017, 15, 409-416. [CrossRef]

52. Sani, G.; Simonetti, A.; Janiri, D.; Banaj, N.; Ambrosi, E.; de Rossi, P.; Ciullo, V.; Arciniegas, D.B.; Piras, F.; Spalletta, G. Association between duration of lithium exposure and hippocampus/amygdala volumes in type I bipolar disorder. J. Affect. Disord. 2018, 232, 341-348. [CrossRef]

53. Luciano, M.; Janiri, D.; Fiorillo, A.; Sani, G. Clinical picture, temperament, and personality of patients with mixed states. Psychiatr Clin. N. Am. 2020, 43, 15-26. [CrossRef]

54. Sani, G.; Tondo, L.; Koukopoulos, A.; Reginaldi, D.; Kotzalidis, G.D.; Koukopoulos, A.E.; Manfredi, G.; Mazzarini, L.; Pacchiarotti, I.; Simonetti, A.; et al. Suicide in a large population of former psychiatric inpatients. Psychiatry Clin. Neurosci. 2011, 65, 286-295. [CrossRef]

55. Verdolini, N.; Dean, J.; Elisei, S.; Quartesan, R.; Zaman, R.; Agius, M. Bipolar disorder: The importance of clinical assessment in identifying prognostic factors-An Audit. Part 2: Mixed state features and rapid cycling. Psychiatr. Danub. 2014, 26, 301-308. 